\title{
APPLICATION OF THE LIKERT AND OSGOOD SCALES TO QUANTIFY THE QUALITATIVE FEATURES OF REAL ESTATE PROPERTIES
}

\author{
Iwona Foryś, Ph.D., Associate Prof. \\ University of Szczecin \\ Faculty of Economics and Management \\ Institute of Econometrics and Statistics \\ Mickiewicza 64, 71-101 Szczecin, Poland \\ e-mail:forys@wneiz.pl \\ Radosław Gaca, MSc, Eng. \\ BBN Domator \\ Gdańska 5/3a, 85-005 Bydgoszcz, Poland \\ e-mail:rgaca@poczta.onet.pl
}

Received 14 December 2015, Accepted 16 November 2016

\begin{abstract}
The variables used in statistical research can be measured on different scales. According to Stevens the most common division of measurement scales distinguish four main types: nominal, ordinal, interval and ratio. The chosen scale of measurement implies further the possibility of applying certain statistical methods. For socio-economic research it is frequent that among independent variables appear variables of a qualitative nature. This study presents the idea of the application of the Likert and Osgood scales for the evaluation and quantification of qualitative variables in the real estate valuation process.

Taking into account the fact that the property features used in the process of estimating its value are very often measured on weak scales, this research attempted to apply the aforementioned scales to measure the qualitative features of real estate property. Additionally, all the qualitative data can be expressed only on nominal or ordinal scales. This means that they cannot be uncritically treated as metrical variables and their measurement scale implies the possible application of mathematical operations and statistical instruments. On the other hand, by analysing the type and the character of the qualitative features of the property, we can observe a substantial connection of such features with the assessment of their level of intensity expressed as a semantic interval or the acceptance level of a given phenomenon. This paper attempts to show how to apply the scales developed to measure attitudes in order to quantify the qualitative features of real estate property in the valuation process and shows the interval character of the data measured by the Osgood scale through comparison among three correlations specific for the mentioned type of scale.
\end{abstract}

Keywords: real estate valuation, measuring scales, qualitative variables

JEL classification: C50, R30 


\section{Introduction}

The key issue in the process of real estate valuation is the nature of the variables that describe the features of a property. The problem of the quantification of those features has so far been the subject of numerous studies (Batóg, Foryś, 2013; Prystupa, 2015; Bełej, Źróbek, 2000). In the mentioned publications the authors, however, did not engage in any broader discussion on the admissibility of the operations on numbers from the perspective of measurement scales.

Those were introduced into the theory of measurement by Stevens (Stevens, 1946) who distinguished nominal, ordinal, interval and ratio scales and ordered them from the weakest (nominal) to the strongest one (ratio scale). In accordance with the principles of measurement, the specific type of scale enables further only a limited group of transformations, as well as arithmetic operations (Walesiak, 1996). The data represented on the scale of a lower level (nominal or ordinal) have always a discrete distribution, whereas those represented on the interval or ratio scale may have both discreet or continuous distributions. This means that the numerical data expressed on the nominal or ordinal scale do not have the typical for natural numbers interpretation. For data expressed on those scales the numbers are codes for differentiating and positioning purpose. The indicated numbers do not describe in the classical sense the distance (interval) or quotient (ratio) of individual variables.

According to one of the fundamental principles of the measurement theory, the measurement results expressed on the stronger scale can be transformed only into numbers belonging to the weaker scale. The reverse data transformation process involving their strengthening is not possible. This results from the simple fact related to the amount of information carried by the measurement (Walesiak, 1996; Wiśniewski, 1986). There are methods of transforming the data measured on the ordinal scale into the interval scale; however, this transformation will not cause an increase in the amount of information contained by the transformed data (Walesiak, 2014).

In the valuation process, among the analysed features of the property significantly influencing the formation and differentiation of prices, there is a whole range of the features of a qualitative nature. Additionally, all the qualitative data can be expressed only on the nominal or ordinal scales. This means that they cannot be uncritically treated as metrical variables (e.g. measured on the interval scale), and their measurement scale implies the possible application of mathematical operations and statistical instruments. On the other hand, by analysing the type and the character of the qualitative features of the property, one can observe a substantial connection of such features with the assessment of their level of intensity expressed as a semantic interval or the acceptance level of a given phenomenon. This research attempt to apply the 
scales developed to measure attitudes in order to quantify the qualitative features of real estate property in the valuation process. To the scales of this type we can include the ones developed by Likert and Osgood.

\section{The Likert and Osgood scales}

The first of these scales was developed by Rensis Likert in 1932, several years before the presentation of the measurement scales concept by Stevens. The original idea of Likert involved the creation of a measurement scale referring to the measurement of opinions, attitudes and views of the respondents connected to the question posed in a questionnaire (Likert, 1932). In the proposed approach the scale has a central value indicating a neutral attitude towards a particular notion or phenomenon and accordingly the values corresponding to the attitudes of negation and acceptance of various intensity. The scale most commonly has five degrees: strongly disagree, tend to disagree, I have no opinion, tend to agree, and strongly agree. It can also be expressed shorter: no, rather not, no opinion, rather yes, and yes. Alternatively, with respect to the level or the state of the feature, the following degrees could be proposed: completely irrelevant, not very relevant, neutral, relevant, and very relevant. The attitude of the respondent can also be expressed using other terms with a greater or lesser gradation.

The concept of the Osgood scale, also referred to as the semantic scale or the semantic differential, was presented for the first time in 1957 (Osgood et al., 1957). In contrast to the Likert scale, this concept focuses more on assessing the level of intensity of a phenomenon or the state of the object that is perceptible by the respondent through specifying it in the semantic form. The authors of the study assumed that the measurement of the connotative meaning comes down to indicating the position that the given notion or name occupy in the semantic space. The analyses conducted by Osgood showed that the basic dimensions of a particular semantic space include: value, strength and activity. He indicated that depending on the purpose and needs of the study, it is possible to use different rankings of the extreme and neutral expressions, corresponding to the abovementioned three universal dimensions.

The properties of the described scales allow us to treat the generated data as the data of interval nature (semi-interval). This fact can be regarded as very attractive from the application point of view for micro-econometric analyses, in particular for those relating to methods of determining the value of real estate. The described nature of the scales results from their construction based on the assessment of the 'position' of the attitude or opinion in relation to the average state (neutral) and the extreme states in the given group. In practice, as the designators 
(quantifiers, codes) of the individual states are used either natural numbers, where the lowest rating is determined by number 1 , or integers, where the average (neutral) rate is determined by number 0 , the states above the average by natural numbers and the states below by negative integers. In each of the described coding systems it is, however, possible to determine the interval between the established values, which allows us to apply to the analysis of the results the methods that are suitable for the interval scale. The admissibility of such an approach is suggested by many authors (Batóg, Foryś, 2013; Gaca, Sawiłow, 2014; Knapp, 1990; Walesiak, Dudek, 2007). It should also be noted that this approach used for the valuation of real estate has a legal basis. The method of measuring the variability of features is in fact used in every valuation conducted using a comparative approach for which the prices are adjusted due to the influence of the qualitative features. Mathematically, for the data quantified using the Likert and Osgood scales it is possible to compare the differences between the values of the variable in the study group, and to make calculations of the arithmetic mean, variance, standard deviation and consequently the linear correlation coefficients, which enable a wider use of econometric models to estimate the value of the property.

\section{Application of the described measurement scales in the process of real estate valuation}

In the process of real estate valuation the features of the property are represented by the variables expressed on different scales of measurement. For each type of scale one can distinguish features that can be expressed on it:

- nominal - presence or absence of a component, factor, e.g. availability of particular utilities, presence of the element of a particular type,

- ordinal - diversity within the given qualitative feature, e.g. assessment of a technical and functional state, assessment of the quality of location, assessment of the quality of land development etc.,

- interval - diversity within the given feature together with the possibility of determining the distance between the measured values, e.g. noise level in the neighbourhood of the property measured in decibels $[\mathrm{dB}]$,

- ratio - diversity within the given feature together with the possibility of determining the distance and the ratio between the measured values, e.g. surface and cubic measures.

Taking into account the previously discussed conditions regarding the construction of the Likert and Osgood scales, in the further part of the paper we attempt to apply the scales to 
assess the qualitative features of a property. In the case of the Likert scale it is possible to evaluate a particular qualitative feature through the answer to the question e.g. about the level of acceptance of the specific location, the functional layout, the position on the floor etc. In this regard, this scale is more predisposed to being used for the initial analysis of buyers' preferences on specific local real estate markets carried out through various types of surveys. Below are examples of the kinds of questions with scales of assessments based on the method proposed by Likert:

- location of the property in the central part of the city should be considered beneficial (strongly disagree, tend to disagree, I have no opinion, tend to agree, and strongly agree),

- location of the property on the first floor should be considered beneficial (strongly disagree, tend to disagree, I have no opinion, tend to agree, and strongly agree),

- the technical and functional state of the building is: completely irrelevant, not very relevant, neutral, relevant, and very relevant.

In the case of the Osgood scale it is possible to conduct the assessment covering a direct evaluation of the feature. The most frequently used terms are here evaluative ones such as average, good, very good; small, medium, or large, etc. In accordance with the theoretical assumptions underpinning the concept of the used scale, the value in the middle of the scale must correspond to the average intensity of the feature in the given group.

An extremely important element in this regard is also the correct definition of ranges of maximum and minimum rates. Based directly on the Osgood scale concept, the scale of the best properties is the one having ranges of extreme rates corresponding to the universal sense of valuation applicable to the given community. However, taking into account the need of creating the model of real estate valuation in the comparative approach based on similar real estate properties, it should be noted that in most cases the level of differentiation of certain features in the study group will be smaller and it will constitute only a part of the total rate span. Below are examples of the kinds of rates with scales based on the method proposed by Osgood:

- location: 1 - medium, 2 - satisfactory (average), 3 - good,

- technical and functional state: 1 - medium, 2 - medium $(+), 3-\operatorname{good}($ average), $4-\operatorname{good}(+), 5-$ very good or $1-\operatorname{medium}(+), 2 \operatorname{good}($ average), $3-\operatorname{good}(+)$ or 1 - good, $2-\operatorname{good}(+)$ (average), 3 - very good.

The examples show that in the case of the valuation of features of the property using the concept of Osgood, for each analysed group it is necessary to make a specific scaling of ratings 
corresponding to the diagnosed extreme states and the average state. Also the gradation range of the scale has to be adapted to the intensity of the feature differentiation. From the direct analysis of appraisal studies results that this rule is often ignored in valuation practice.

\section{Empirical research}

In order to test the hypothesis concerning the interval and even distribution of the variation of the individual states of qualitative features quantified using the Osgood scale, we calculated the correlation of the individual features in relation to the corrected prices of similar real estate properties to the state ceteris paribus. For this purpose the following correlations were used: Pearson's linear correlation, Spearman's rank correlation and Kendall's Tau correlation. It should be additionally noted that although the types of measurement scales were very precisely defined, until now no tests have been created that would enable an unambiguous assessment of the type of scale on which the variables are expressed. To confirm the hypothesis we assumed that the results of all the correlations should be convergent. Because of the different structure of the correlation measure for Kendall's Tau in relation to the other two correlations, the comparison was made taking into account relative values, representing the percentage share of each correlation coefficient in relation to their sum. We assumed that due to the construction of each correlation measurement, convergent results in relative terms would be possible to obtain only in a situation in which the qualitative variables quantified using the Osgood scale would behave as at least interval variables.

The calculation of the correlation coefficients for the individual features was conducted in relation to the corrected features of the similar properties with regard to the principle ceteris paribus, making appropriate price adjustments taking into account the differences in the assessment of the features relative to the median of these assessments (Gaca, Sawiłow, 2014). First, the matrix A was filled with the values of individual features for the analysed set of n-similar properties $a_{i j}$, where: $i=1,2, \ldots, n, j=1,2, \ldots, m$ and their transaction prices $c_{i}$, where: $i=1,2, \ldots, n$ :

$$
\mathbf{A}=\left[\begin{array}{cccc}
a_{11} & \ldots & a_{1 m} & c_{1} \\
a_{21} & \ldots & a_{2 m} & c_{2} \\
\ldots & \ldots & \ldots & \ldots \\
a_{n 1} & \ldots & a_{n m} & c_{n}
\end{array}\right]
$$


The information contained in the matrix A, provide initial data to determine the value of the property using a comparative approach. ${ }^{1}$ Market features including qualitative variables were quantified using the Osgood scale. According to the indicated method, three correlation coefficients were calculated for the individual qualitative features quantified using the Osgood scale in relation to the adjusted prices of real estate. Price adjustments and the calculation of adjusted prices were made in accordance with the formulas:

where:

$$
C s_{i j}=C_{i}-\Delta C \times\left(1-W k_{i j}\right)
$$

$C s_{i j}-$ adjusted unit price of the $i$-th property for the $j$-th feature,

$c_{i} \quad-$ unit price of the $i$-th property before adjustment,

$\Delta C$ - the difference between the maximum and minimum unit price observed in the set,

$W k_{i j}$ - unit price correction coefficient of the $i$-th property for the $j$-th features to the state 'ceteris paribus' in relation to the other states of the features calculated using the equation:

where:

$$
W k_{i j}=\frac{-M e_{j}+\sum_{j=1}^{m} M e_{j}}{-x_{i j}+\sum_{j=1}^{m} x_{i j}},
$$

$M e_{j}-$ median of the rate scale of the $j$-th feature of the set of rates for this feature assigned to the properties from the study set, $j=1, \ldots, m$;

$x_{i j} \quad-$ assessment of the level of the $j$-th feature on the adopted scale for the $i$-th property.

Based on the calculations we obtained the matrix of adjusted prices $C_{S n m}$ :

$$
Y=\left[\begin{array}{cccc}
C s_{11} & \ldots & C s_{1 m-1} & C s_{1 m} \\
C s_{21} & \ldots & C s_{2 m-1} & C s_{2 m} \\
\ldots & \ldots & \ldots & \ldots \\
C s_{n 1} & \ldots & C s_{n m-1} & C s_{n m}
\end{array}\right]
$$

The adjusted prices obtained in the matrix include the influence on their formation of all analysed features by taking into account their relation to the center value. This means that by the calculation of the correlation coefficients for the individual features, the variation occurring for the other features is eliminated. It is, therefore, a mathematical transformation leading all the

\footnotetext{
${ }^{1}$ Matrix A, which characterizes the analyzed group of similar properties within the meaning of Art. 4 paragraph 16 of the Act of 21 August 1997 on real estate management provides the basis for the determination of the influence of the individual features on the differentiation of prices.
} 
other features of all analysed similar properties to the state 'ceteris paribus'. In order to simplify the further calculations it was assumed that for the analysed groups of real estate properties there was no change in the price level over time.

The following variables were distinguished as differentiating features of residential real estate properties in qualitative terms: location (X1), technical and functional state of the building (X2), technical and functional state of the premises (X3), floor on which the premises is located (X4), the area of the premises (X5). The study involved two sets of similar properties (45 and 50 observations) located within the central housing estates of Bydgoszcz, which areas were in different size ranges.

The adopted rating scale of qualitative features (the Osgood scale):

X1 1 - medium, 2 - medium $(+), 3$ good, $4-\operatorname{good}(+), 5$ - very good;

X2 1 medium, 2 medium (+), 3 good, 4 good (+), 5 very good;

X3 1 medium, 2 medium (+), 3 good, 4 good (+), 5 very good.

For the feature X4 we adopted a three-degree scale: medium (1) the first and fourth floor, good (2) the third floor, very good (3) the second floor. The X5 feature was transformed into a qualitative variable using the method of set discrimination into equivalent subsets, each covering 20 percentile of the total count. We adopted the rating scale (1-5), provided that the quality of the feature decreases with the increasing area, for the ranges of the area for the analysed sets from $0.25 \mathrm{~m}^{2}$ to $78.05 \mathrm{~m}^{2}$ and from $80.08 \mathrm{~m}^{2}$ to $127.95 \mathrm{~m}^{2}$. Table 1 lists the calculated three correlation coefficients for the set of similar properties of the larger area (45 observations) and the smaller area (50 observations).

Table 1. Correlation coefficients for the set of similar properties

\begin{tabular}{|c|c|c|c|c|c|c|}
\hline \multirow{2}{*}{$\begin{array}{l}\text { Qualitative } \\
\text { features }\end{array}$} & \multicolumn{2}{|c|}{ Spearman correlation } & \multicolumn{2}{|c|}{ Pearson correlation } & \multicolumn{2}{|c|}{ Kandall's Tau correlation } \\
\hline & $\mathrm{r}_{\mathrm{s}}$ & share $\%$ & $r_{x y}$ & share $\%$ & $\tau$ & share $\%$ \\
\hline \multicolumn{7}{|c|}{ The premises of the larger areas $\left(80.08-127.95 \mathrm{~m}^{2}\right)$} \\
\hline $\mathrm{X} 1$ & 0.60547 & 24.82 & 0.53027 & 23.74 & 0.33773 & 24.59 \\
\hline $\mathrm{X} 2$ & 0.45744 & 18.75 & 0.40178 & 17.99 & 0.22986 & 16.73 \\
\hline $\mathrm{X} 3$ & 0.61538 & 25.22 & 0.61830 & 27.68 & 0.39367 & 28.66 \\
\hline $\mathrm{X} 4$ & 0.33458 & 1371 & 0.25354 & 11.35 & 0.18440 & 13.43 \\
\hline $\mathrm{X} 5$ & 0.42684 & 17.50 & 0.43005 & 19.25 & 0.22791 & 16.59 \\
\hline \multicolumn{7}{|c|}{ The premises of the smaller areas $\left(50.25-78.05 \mathrm{~m}^{2}\right)$} \\
\hline $\mathrm{X} 1$ & 0.37962 & 22.34 & 0.23671 & 19.13 & 0.18587 & 19.86 \\
\hline $\mathrm{X} 2$ & 0.39558 & 23.28 & 0.28263 & 22.85 & 0.21088 & 22.53 \\
\hline $\mathrm{X} 3$ & 0.57188 & 33.65 & 0.54071 & 43.71 & 0.36258 & 38.74 \\
\hline $\mathrm{X} 4$ & 0.10007 & 5.89 & 0.02500 & 2.02 & 0.04751 & 5.08 \\
\hline $\mathrm{X} 5$ & 0.25239 & 14.85 & 0.15209 & 12.29 & 0.12919 & 13.80 \\
\hline
\end{tabular}

Source: own calculations. 
The results indicate a very broad convergence of relative values of correlation coefficients calculated using the described methods. The differences in shares for each variable are on the level of $2-3 \%$ for both larger and smaller premises, which proves the advantage of the proposed method. Only for the variable X3 (technical and functional state of the premises) in the case of the smaller premises there was a difference of a $10 \%$ share of the variable between the Spearman and Pearson correlations. This circumstance may be associated with the accepted method of discrimination, which will be the subject of further examination.

\section{Conclusions}

As is shown in this paper, the application of the Likert and Osgood scales for the assessment and quantification of the features of real estate properties in the valuation process is possible and leads to the improved objectivity of ratings, and consequently to increased objectivity of the valuation process. The empirical example shows a very broad convergence of relative values of correlation coefficients calculated using the described methods. The results indicate the possibility of treating the qualitative data expressed using the Osgood scale as data expressed using at least an interval scale.

From the analysis of past experience and the practice of appraisers results that much more often for assessment and further quantification of the level of the qualitative feature they use a semantic differential. The Likert scale in its original form is used more frequently to analyse the attitudes of potential buyers in the initial research of determinants on the local markets. The proposed solutions, on the other hand, can not only significantly contribute to a better understanding of the motives of real estate market participants but also leads to the increased objectivity of real estate valuation.

\section{References}

Act of 21 August 1997 on real estate management (Journal of Laws of 2005, item 782, as amended).

Batóg, B., Foryś, I. (2013a). Zastosowanie modeli zmiennych jakościowych do badania wpływu cech mieszkań na cenę rynkową kwalifikującą je do finansowania w programie „Rodzina na swoim". Wiadomości Statystyczne, 5 (624), 36-50. 
Batóg, B., Foryś, I. (2013). Modele cen nieruchomości mieszkaniowych na rynku lokalnym. In: B. Pawełek (ed.), Zastosowanie metod ilościowych $w$ modelowaniu i prognozowaniu zjawisk społeczno-gospodarczych (pp. 220-234). Kraków: Wydawnictwo Uniwersytetu Ekonomicznego w Krakowie.

Gaca, R. Sawiłow, E. (2014). Korygowanie stanów cech nieruchomości do stanu „ceteris paribus" przy ustaleniu wag cech rynkowych nieruchomości z zastosowaniem korelacji rang Spearmana. Rzeczoznawca Majątkowy, 83, 48-51.

Knapp, T.R. (1990). Treating ordinal scales as interval scales: an attempt to resolve the controversy. Nursing Research, 39 (2), 121-123.

Likert, R. (1932). Technique for the Measurement of Attitudes Archives of Psychology, 140, $1-55$.

Osgood, C.E., Suci, G., Tannenbaum, P. (1957). The measurement of meaning. Urbana, IL: University of Illinois Press.

Prystupa, M. (2014). Wycena nieruchomości i przedsiębiorstw w podejściu porównawczym. Wydawnictwo Replika, Polska Federacja Stowarzyszeń Rzeczoznawców Majątkowych.

Stevens, S.S. (1946). On the theory of scales of measurement. Science, 103 (2684), 677-680.

Walesiak, M. (1996). Dopuszczalne działania na liczbach w badaniach marketingowych z punktu widzenia skal pomiarowych. Prace Naukowe Akademii Ekonomicznej we Wrocławiu, 718, 103-110.

Walesiak, M. (2014). Wzmacnianie skali pomiaru w statystycznej analizie wielowymiarowej. Prace Naukowe Akademii Ekonomicznej we Wrocławiu, 327, 60-68.

Walesiak, M., Dudek, A. (2007). Symulacyjna optymalizacja wyboru procedury klasyfikacyjnej dla danego typu danych - charakterystyka problemu. Zeszyty Naukowe Uniwersytetu Ekonomicznego we Wrocławiu, Prace Katedry Ekonometrii i Statystyki, 17 (450), 635-646.

Wiśniewski, J.W. (1986). Korelacja i regresja w badaniach zjawisk jakościowych na tle teorii pomiaru. Przegląd Statystyczny, 3, 239-248.

Źróbek, S., Bełej, M. (2000). Podejście porównawcze w szacowaniu nieruchomości. Educaterra 